\title{
Gjøkparasittisme hos heipiplerke: Noen erfaringer fra Øyerfjellet sesongen 2005
}

\author{
Jan Berstad
}

Berstad, J. 2008. Common Cuckoo Cuculus canorus parasitizing nests of Meadow Pipit Anthus pratensis. Some findings from a mountainous area in Norway. - Ornis Norvegica 31: 98-104.

In a mountainous area of Øyerfjellet 17 nests of the Meadow Pipit Anthus pratensis were found during the season of 2005. Five or possibly six of these nests were parasitized by the Common Cuckoo Cuculus canorus, giving a parasitizing rate of $29.4 \%$ and $35.3 \%$, respectively. The nests were regularly controlled, and two nests were found deserted by the Meadow Pipit probably during the start of the nesting period, whereas three Cuckoo chicks were hatched. Nearly hatched eggs or newly hatched chicks were found ejected from these three Meadow Pipit nests. When comparing the egg clutches from parasitized nests with unparasitized nests, it was roughly estimated that a mean of $1 \frac{1}{2}$ Meadow Pipit eggs were missing in the parasitized nests. All the five Cuckoo eggs had a pale brownish colour. When considering this brownish colour, it was suggested that mimicry of the Meadow Pipit eggs and the Cuckoo egg were slightly better in the three nests of completed hatching than in the two nests being deserted. The pattern and markings of the eggs showed good mimicry between eggs of Meadow Pipit and Cuckoo except for the pigment concentration at the broad end of many Meadow Pipit eggs.

Key words: Common Cuckoo rate of parasitism, Meadow Pipit, mimicry.

Jan Berstad,Lindemannsv.3, N-1453 Bjфrnemyr.E-mail: jan.berstad@sunnaas.no

\section{INNLEDNING}

I 2005 fant jeg fem heipiplerkereir som var parasittert av gjøk samt ett reir hvor gjøkungen kanskje var blitt tatt av predator før den ble ferdig med å tømme reiret helt for egg/unger. Området hvor observasjonene ble gjort var i en del av Øyerfjellet i Gudbrandsdalen med utgangspunkt i Hafjell. I alt 17 heipiplerkereir ble funnet. Lokaliseringen av reiret ble bestemt ved GPS hvor også høgde over havet ble målt. For ikke å skade reirstrukturen, ble eggene tatt ut og lagt tilbake med ei plastskje og lagt over på hvitt lommetørkle for fotografering med speilreflekskamera. Ved fotograferingen ble følgelig bakgrunnen lik, noe som gir standardiserte betingelser ved sammenlikning av eggfargene. Fugler kan sky reiret lettere på eggstadiet enn når det er unger, og unders $\varnothing$ kelsen ble derfor utført svært raskt for deretter å komme seg langt vekk fra reiret fortest mulig. De samme områdene ble gjennoms $\varnothing \mathrm{kt}$ flere ganger og reirene ble alle kontrollert flere ganger. Jeg registrerte ikke at mine forstyrrelser fikk noen av fuglene til å avbryte hekkingen og tilskriver det de to tiltakene nevnt ovenfor.

\section{RESULTATER}

I 17 reir ble det funnet gjøkparasittisme sikkert i fem, og sannsynlig i ett til (Fig. 1) hvor gjøkungen ble antatt å være forsvunnet under sin aktivitet med å tømme reiret uten og bli helt ferdig. Dette 
gir en parasittisme på 29.4\%, men 35.3\% dersom også dette reiret regnes med (Fig. 1).

I 12 heipiplerkereir kunne jeg registrere antall egg i fullagte kull. I disse kullene var antall egg tre i ett reir, fire i tre reir, fem i sju reir og seks i ett reir. Gjennomsnittet blir følgelig 4.67 egg i ikke-parasitterte reir.

I alle de fem heipiplerkereirene som var parasittert av gjøk var det bare ett gjøkegg. Gjenværende heipiplerkeegg var to i ett reir, tre i tre reir og fire $\mathrm{i}$ ett reir (Tabell 1). I reiret med bare to heipiplerkeegg igjen (Fig. 2b; H2005nr 11g2) ble det funnet et tredje egg som lå ca. $1 \frac{1}{2} \mathrm{~m}$ fra reiret. Dette egget ble registrert som fjernet (Tabell 1). Ett reir (H2005nr3gl) ble funnet tidlig morgen med fem egg og med heipiplerka rugende, antakelig samme dag som gjøken la sitt egg seint på dagen og hadde fjernet to heipiplerkeegg (Fig 2a). Samlet gir dette en differanse i gjennomsnittet mellom antall heipiplerkeegg i parasitterte reir $(\mathrm{n}=5)$ og ikke-parasitterte reir $(\mathrm{n}=12)$ på 1.67. Regner man med reiret merket $H 2005 \mathrm{nr} 17 \mathrm{~g}$ ? (Fig. 1) hvor det altså var en levende nyklekt heipiplerkeunge i reiret, og utenfor en død unge og to egg, blir denne differansen 1.50.

I tre av fem reir med gjøkparasittisme ble det verifisert klekking av gjøkunge (eksempel Fig. 3; H2005nr16g5). I to av disse reira ble det funnet henholdsvis ett og tre egg utenfor reirkanten, og i ett reir ble det funnet ett egg og en nyklekket heipiplerkeunge som var død. Sjekk av alle eggene viste store fostre, bedømt til å være like før klekking. I ett reir (H2005nr 17g?) lå heipiplerka og ruget på en nyklekt unge, og utenfor reiret $i$ en avstand som passer med den avstanden gjøkungen vanligvis kaster ut egg og unger ved å tippe de over reirkanten, lå det en død nyklekt unge og to heipiplerkeegg (Fig.1; Tabell 1).

Når det ble lagt til grunn at heipiplerka ruger i 12-13 dager, kunne jeg slutte meg til ut fra hele materialet $(n=17)$ en mulig rugestart fra 8. til 24 . juni. Tidspunkt for antatt rugestart i de gjøkparasitterte reir er angitt i Tabell 1 og strakk seg fra
14. til 24. juni. I de to reirene som ble desertert av heipiplerka ble alle eggene blåst ut og plommene studert. Det ble ikke funnet tegn til inkubasjon hverken for gjøkegg eller heipiplerkeegg.

Fotografering av eggkullene gjør det mulig med visuell vurdering av mimikry (Fig. 2a-e). Det ble observert betydelig likhet mellom kull av heipiplerkeegg og gjøkegg når det gjelder mønster og tegninger. Gjøkeggene hadde alle fem en brunlig farge, og visuelt bedømt syntes det følgelig å være dårligst mimikry i heipiplerkekull med mer sandfargede egg. Når det gjelder brunfarge i de to kullene hvor heipiplerka deserterte, se Fig. 2a-e og Tabell 1, syntes mimikry i forhold til brunfarge å være dårlig. Ingen av gjøkeggene hadde konsentrasjon av pigment rundt den butte enden av eggene, og følgelig var det også dårlig mimikry når det gjelder slik konsentrasjon av pigment.

Fra fotografiene virket gjøkeggene ganske like store $(\mathrm{n}=5)$, og de var større enn heipiplerkeeggene. For hvert av de fem gjøkeggene målte jeg lengde og bredde ut fra fotografiene samt lengde og bredde tilsvarende i det samme reiret for heipiplerkeegg. Radius lengde og radius bredde ble så brukt for å regne ut det relative volum mellom heipiplerkeegg og gjøkegg. I gjennomsnitt var gjøkegget ca. 1 1/2 gang større enn heipiplerkeegg i det samme reiret (Tabell 1).

De 17 heipiplerkereirene ble funnet i områder hvor det var svært lite trær. Mest typisk var det bare spredte trær, men det var aldri helt fritt for trær og aldri helt over den absolutte tregrensa. Høgde over havet for de 17 reirene ble funnet å være i gjennomsnitt $932 \mathrm{~m}$ med en spredning fra 875 til $1018 \mathrm{~m}$.

\section{DISKUSJON}

Disse funnene har gitt mulighet for observasjon av naturlig forekomst av parasittisme ved gjøk av heipiplerkereir tidlig i rugeperioden. Jeg fant også to reir hvor heipiplerka hadde desertert reiret etter at gjøken hadde lagt egget. Eggene til både 


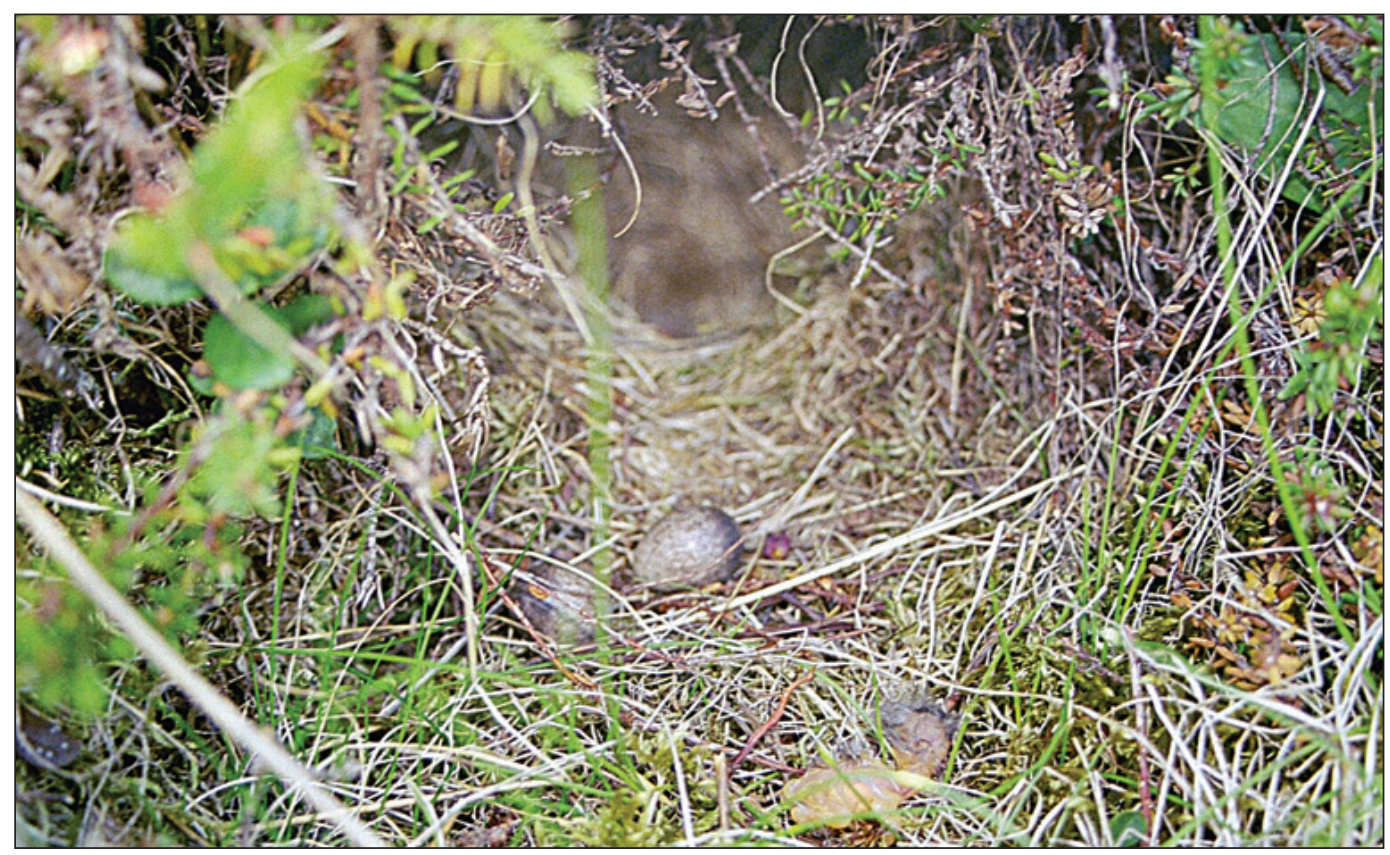

Figur 1. Heipiplerkereir merket H2005nr.17g? . Her var det ingen gjøkunge, men antatt spor etter den. I reiret ruget heipiplerka på en nyklekket levende unge. Nedenfor reiret ses to egg som hadde klekkeferdige fostre samt en død nyklekket heipiplerkeunge. Foto: Jan Berstad.

Tabell 1. Oversikt over heipiplerkereir med gjфkparasittisme. Relativt volum mellom heipiplerke- og gjфkegg $i$ hvert enkelt gjøkeparasittert reir er estimert, og heipiplerkeegg settes til verdien 1.0.

\begin{tabular}{lcccc}
\hline Reir & $\begin{array}{c}\text { Antall gjøk- } \\
\text { + vertsegg }\end{array}$ & $\begin{array}{c}\text { Relativt volum egg } \\
\text { heipiplerke-/gjøk }\end{array}$ & $\begin{array}{c}\text { Anslått } \\
\text { rugestart }\end{array}$ & Reirhistorie \\
\hline H2005nr3g1 & $1+3$ & 1.4 & 14 juni & Desertering \\
H2005nr11g2 & $1+2$ & 1.5 & 16. juni & Suksess \\
H2005nr14g3 & $1+3$ & 1.6 & 16. juni & Suksess \\
H2005nr15g4 & $1+3$ & 1.6 & 24. juni & Desertering \\
H2005nr16g5 & $1+4$ & 1.5 & 15. juni & Suksess \\
H2005nr17g? & $0+2+2 \mathrm{u}$ & & 19. juni & Predasjon? \\
& & & & \\
\hline
\end{tabular}



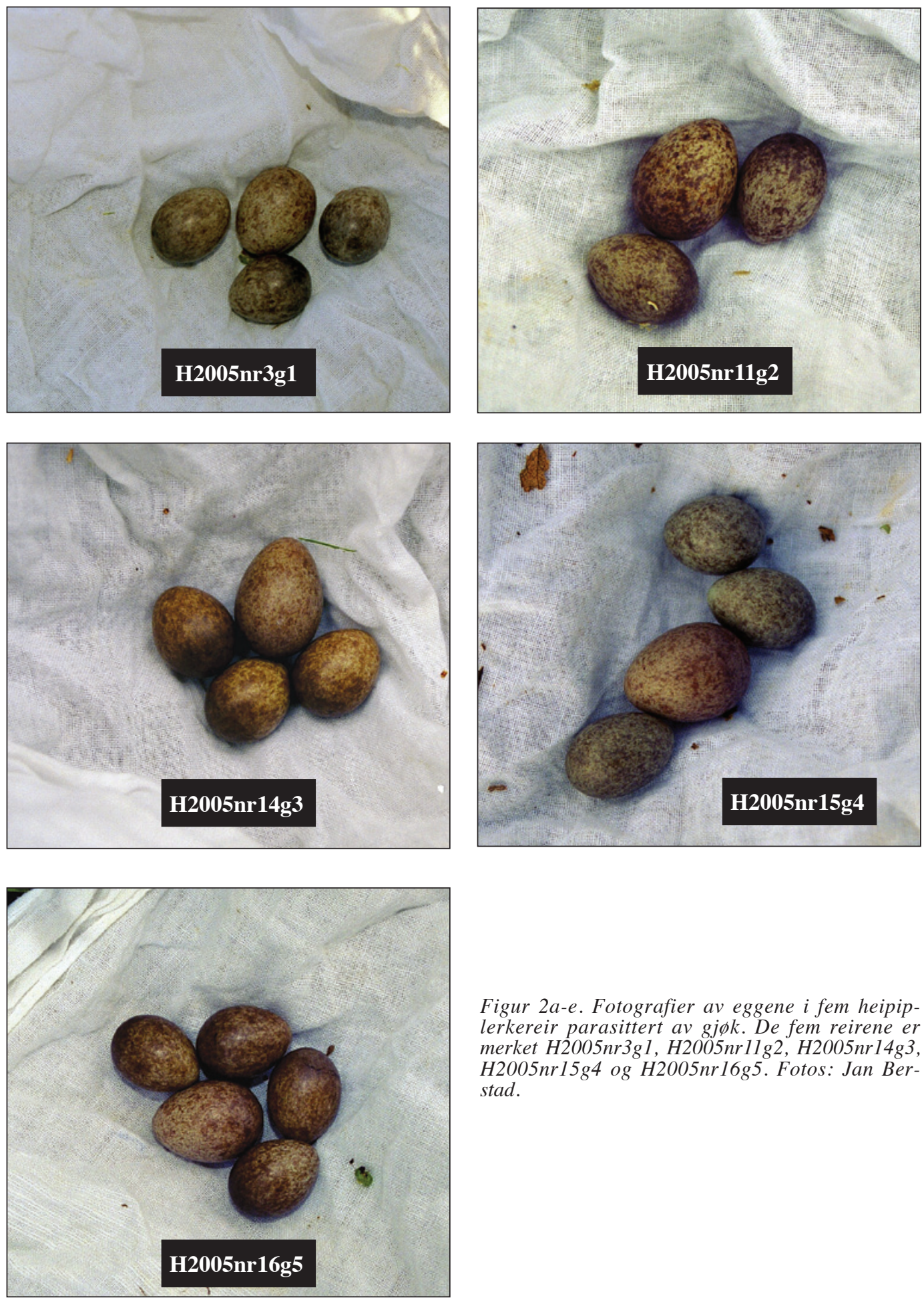

Figur 2a-e. Fotografier av eggene i fem heipiplerkereir parasittert av gjøk. De fem reirene er merket H2005nr3g1, H2005nr11g2, H2005nr14g3, H2005nr15g4 og H2005nr16g5. Fotos: Jan Berstad. 
gjøk og heipiplerke hadde ferske plommer i disse to reirene, noe som gir sterke holdepunkter for at heipiplerkene hadde desertert like etter gjøkenes eggleggingsvisitt. Det aktuelle materialet er relativt lite, men observasjonene kan likevel være interessante når de sammenliknes med større materialer om reirparasittisme av gjøk (se Moksnes 1994, Stokke 2001).

Alle de fem observerte gjøkeggene hadde en lysebrun farge, mens heipiplerka legger egg med varierende farge $\mathrm{i}$ et kontinuum fra veldig brune til mer grålige eller «sandfargede» egg. Gjøkeggene liknet ved visuell bedømmelse av både farge og mønster samt av tegninger veldig på eggene til heipiplerka og derved syntes det ved første øyekast å være god eggmimikry, men ingen av gjøkeggene hadde konsentrasjon av mørkere farge i den butte enden slik som heipiplerkeeggene ofte har (Fig. 2a-e). Denne brunfargen av gjøkegget var ikke tilstede ved funn av reirparasittisme ved gjøk i ett heipiplerkereir som jeg gjorde i 2002 på Filefjell (Fig. 4). Materialet er for lite til å uttale seg om de to reirene som ble desertert hadde dårligere eggmimikry mellom heipiplerkeegg og gjøkegg enn de andre som ikke ble desertert, men ett av de to deserterte reira syntes å ha spesielt dårlig mimikry når det gjelder brunfarge (Fig. 2d). Når det gjelder mønster og avtegninger som gir eggene et flekkete (spraglete) utseende, syntes det å være god mimikry mellom heipiplerkeeggene og gjøkeggene (Fig. 2a-e). Det er et faktum at gjøk som parasitterer heipiplerke legger egg som likner på eggene til heipiplerka, men vi vet imidlertid ikke hvor vesentlig mimikry er for at heipiplerka vil desertere. Moksnes m.fl. (1993) fant ved eksperimenter holdepunkter for at mimikry ikke kunne være av stor betydning. Andre forhold kan være av større betydning for desertering. Moksnes \& Røskaft (1989) og Moksnes m.fl. (1993) kunne ved sine eksperimenter med en utstoppet gjøk og kunstige gjøkegg vise at kombinasjonen av gjøkegg i reiret og synet av en gjøk $\emptyset \mathrm{kte}$ heipiplerkas deserteringsrate betydelig.

Hyppigheten av gjøkparasittisme av de17 heipip- lerkereirene var stor i dette materialet, og ble funnet til å være 29.4, eventuelt 35.3\%. Dette er mye høgere enn tidligere egne erfaringer fra funn av heipiplerkereir på Filefjell, også her under tregrensa. Det synes også å være høgere enn det som ble funnet av Moksnes \& Røskaft (1987) hvor de fant parasittisme på henholdsvis $6.4 \%$ og $25.0 \%$ hos heipiplerke i høyereliggende $(n=$ 329) og lavereliggende $(n=12)$ subalpine/alpine områder i Midt-Norge. Ved registrering av hele 5331 heipiplerkereir i Storbritannia, er det angitt en gjennomsnittlig reirparasittisme av gjøk på $3 \%$ (Glue \& Murray 1984). Noe av forklaringen på den høge parasittismen i det aktuelle materialet fra Øyerfjellet kan være at reirene ble funnet så tidlig at jeg også fikk inkludert reir som ble desertert svært tidlig. Hyppigheten av gjøkparasittisme i det aktuelle området kan også ha vært uvanlig høg i 2005. I det samme området fant jeg i 2004 at to av 13 heipiplerkereir var parasittert (15.4\%), men begge disse funnene var av gjøkunge som var klekket.

Når gjøkhunnen legger sitt egg i vertsreiret pleier hun å ta ett vertsegg i nebbet og legger deretter kjapt sitt eget egg direkte i reiret (Wyllie 1981, Moksnes 1994). Deretter flyr hun bort og svelger egget som hun har i nebbet dersom det ikke er svelget allerede (Ericson \& Sjøgren 2004). Det er kjent at noen ganger fjerner hun mer enn ett egg, og det synes å være gode holdepunkter for at dette faktisk skjedde også i den aktuelle studien.

Det hevdes at gjøken kan legge svært mange egg, og videre ett egg annenhver dag (Chance 1940). Antall egg som legges av gjøkhunnen pr. sesong kan nok variere mye (Ericson \& Sjøgren (2004), men det synes ikke å være tvil om at en gjøkhunn har potensial i seg til å legge mange egg. Wyllie (1981) studerte gjøkparasittisme hos rørsanger i en periode på 6 år (1974 - 1979) i Øst-England. Ved å observere merkede individer og å identifisere gjøkhunnen indirekte ved å gjenkjenne eggene, klarte han å følge 19 hunner som hver sesong la fra 2 til 15 egg med et gjennomsnitt på 8. Man kan derfor undre seg over hvordan gjøkhunnen kan klare å finne nok reir som den 
kan parasittere. I mine funn fra Øyerfjellet var imidlertid tidspunktet for rugestart for heipiplerka spredt ganske mye ut i tid. Slik spredning i tid for egglegging gjør det lettere for gjøken å finne nok vertsreir for sine egg.

I det aktuelle materialet bekreftes det to kjente strategier ved gjøkens reirparasittisme. For det første fant jeg at egg som ble løftet ut av gjøkungen fra heipiplerkereir hadde store og klekkeferdige fostre, og også nyklekte unger ble løftet ut. Dette viser den velkjente synkroniseringen av klekkingen av gjøkegget litt før klekkingen av heipiplerkeegget. For det andre var gjøkeggene grovt estimert til å være ca. $1 / 2$ gang større enn eggene til verten (Tabell 1). Dette gir den nyklekte gjøkungen et markert fortrinn vektmessig når den skal klare den kraftprestasjonen som det må være å løfte egg eller unger ut av reirskåla.

I det aktuelle materiale ble tre gjøkunger klekt (Tabell 1), og disse overlevde til en fem-seks dager etter klekkingen hvor observasjonene ble avsluttet. Regnes også reir nr. 17 med hvor det ikke er sikkert at reiret var parasittert, blir dette en hekkesuksess på 50\%. Det er kjent fra litteraturen at hekkesuksess for gjøk kan variere mye, Kleven m.fl. (2004) fant en hekkesuksess på $44.8 \%$ hos myrsanger Acrocephalus palustris, $33.8 \%$ hos trostesanger $A$. arundinaceus, $26.5 \%$ hos sivsanger $A$. schoenobaenus og bare $11.6 \%$ hos rørsanger A. cirpaceus.

Gjøk kan ofte observeres over tregrensa, men det er uklart om den klarer å utnytte heipiplerka som hekker der som vert for sine egg. Det hevdes at gjøkhunnen trenger trær for spaning (Øien m.fl. 1996, Røskaft m.fl. 2002). Jeg fant ved denne unders $\varnothing$ kelsen et heipiplerkereir som var parasittert av gjøk helt opp til 1018 m over havet, men i det aktuelle området var det flere forblåste grantrær selv om de riktig nok stod veldig spredt. I nærheten av dette reiret ble det også funnet heipiplerkereir med gjøkunge i 2004, og nå i $1050 \mathrm{~m}$ høgde over havet. Her var det også et par forblåste små grantrær i nærheten, selv om disse trærne sto nesten aleine og i stor avstand på fjellet rundt dette reiret.

\section{TAKK}

Heipiplerkereirene ble funnet ved hjelp fra Øyvind Traagstad, Inge Selås og Jess HolmboeErichsen som også har kommet med råd ved utarbeidelsen av artikkelen.

\section{REFERANSER}

Chance, E.P. 1940. The Truth about the Cuckoo. Country Life, London.

Ericson, P.G.P. \& Sjøgren, H. 2004. Boken om Göken. Atlantis, Stockholm.

Glue, D. \& Murray, E. 1984. Cuckoo hosts in Britain. - British Trust of Ornithology News 134:5.

Kleven, O., Moksnes, A., Røskaft, E., Rudolfsen, G., Stokke, B.G. \& Honza, M. 2004. Breeding success of common cuckoos Cuculus canorus parasitising four sympatric species of Acrocephalus warblers. - J. Avian Biol. 35: 394-398.

Moksnes, A., Røskaft, E. 1987. Cuckoo host interactions in Norwegian mountain areas. - Ornis Scand. 18: 168-172.

Moksnes,A., Røskaft, E. 1989. Adaptation of meadow pipits to parasitism by the common cuckoo. - Behav. Ecol. Sociobiol. 24: 25-30.

Moksnes, A., Røskaft, E. \& Korsnes, L. 1993. Rejection of cuckoo (Cuculus canorus) eggs by meadow pipit (Anthus pratensis). - Behav. Ecol. 4: 120-127.

Moksnes, A. 1994. Gjøk Cuculus canorus. S. 268 i: Gjershaug, J.O., Thingstad, P.G., Eldøy, S. \& Byrkjeland, S. (red.): Norsk fugleatlas. Norsk Ornitologisk Forening, Klæbu. $552 \mathrm{~s}$.

Røskaft, E., Moksnes, A., Stokke, B.G., Moskát, C. \& Honza, M. 2002. The spatial habitat structure of host populations explains the pattern of rejection behavior in hosts and parasitic adaptations in cuckoos. - Behav. Ecol. 13: 163-168.

Stokke, B.G. 2001. Coevolutionary adaptations in avion brood parasites and their hosts. Dr. scient. thesis, Department of Zoology, NTNU, Trondheim.

Wyllie, I. 1981. The Cuckoo. In: Shire Natural History series, $n r$. 23. Shire Publications Ltd. UK.

Øien, I.J., Honza, M., Moksnes, A. \& Røskaft, E. 1996. The risk of parasitism in relation to the distance from reed warbler nests to cuckoo perches. - J.Anim. Ecol. 65: 147-153. 


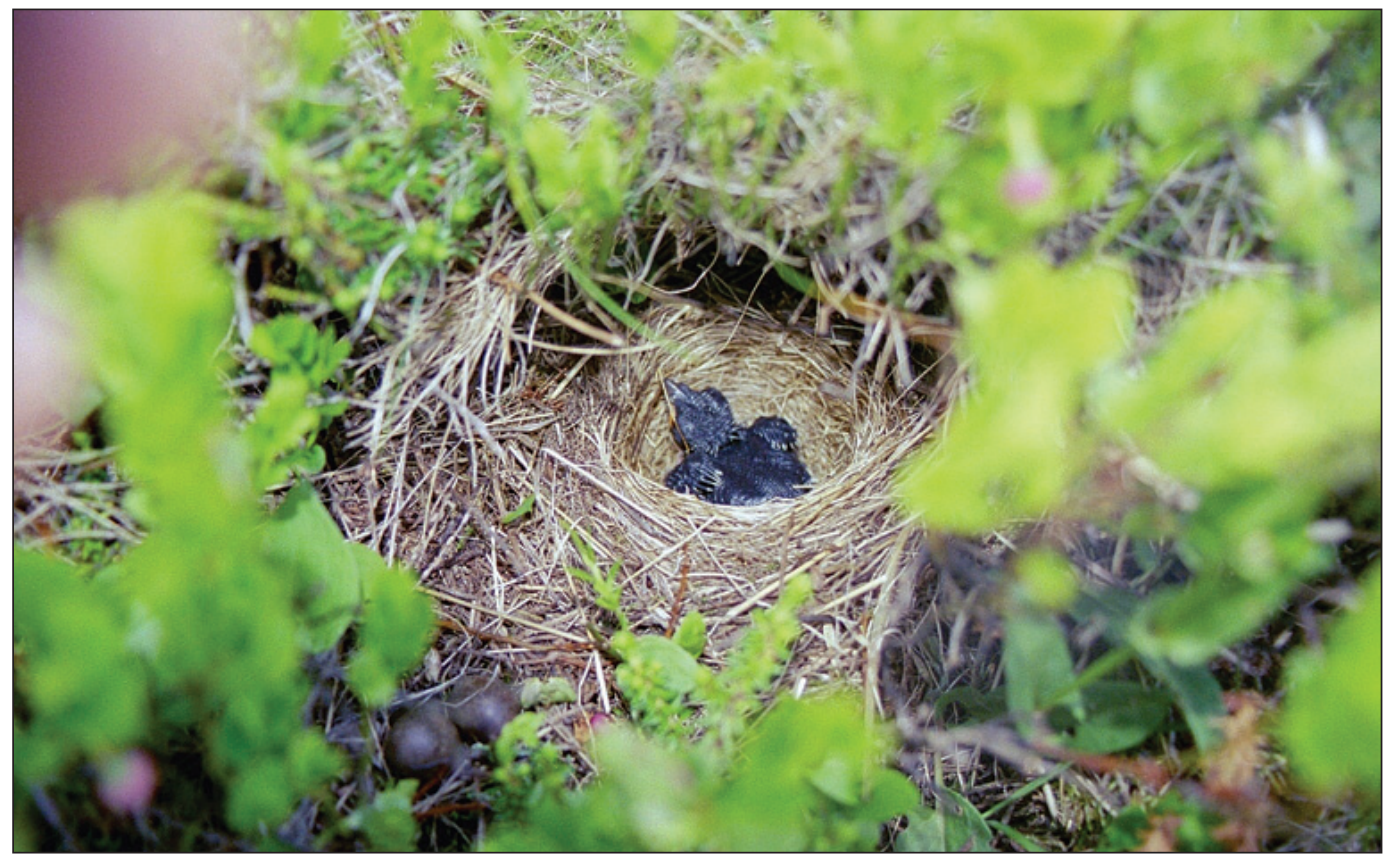

Figur 3. Gjфkunge som er klekket og har lфftet eggene til heipiplerka ut av reiret (H2005nr16g5). To egg ses på bildet ned til venstre, og har rullet litt nedoverbakke. Eggene hadde klekkeferdige fostre. Foto: Jan Berstad.

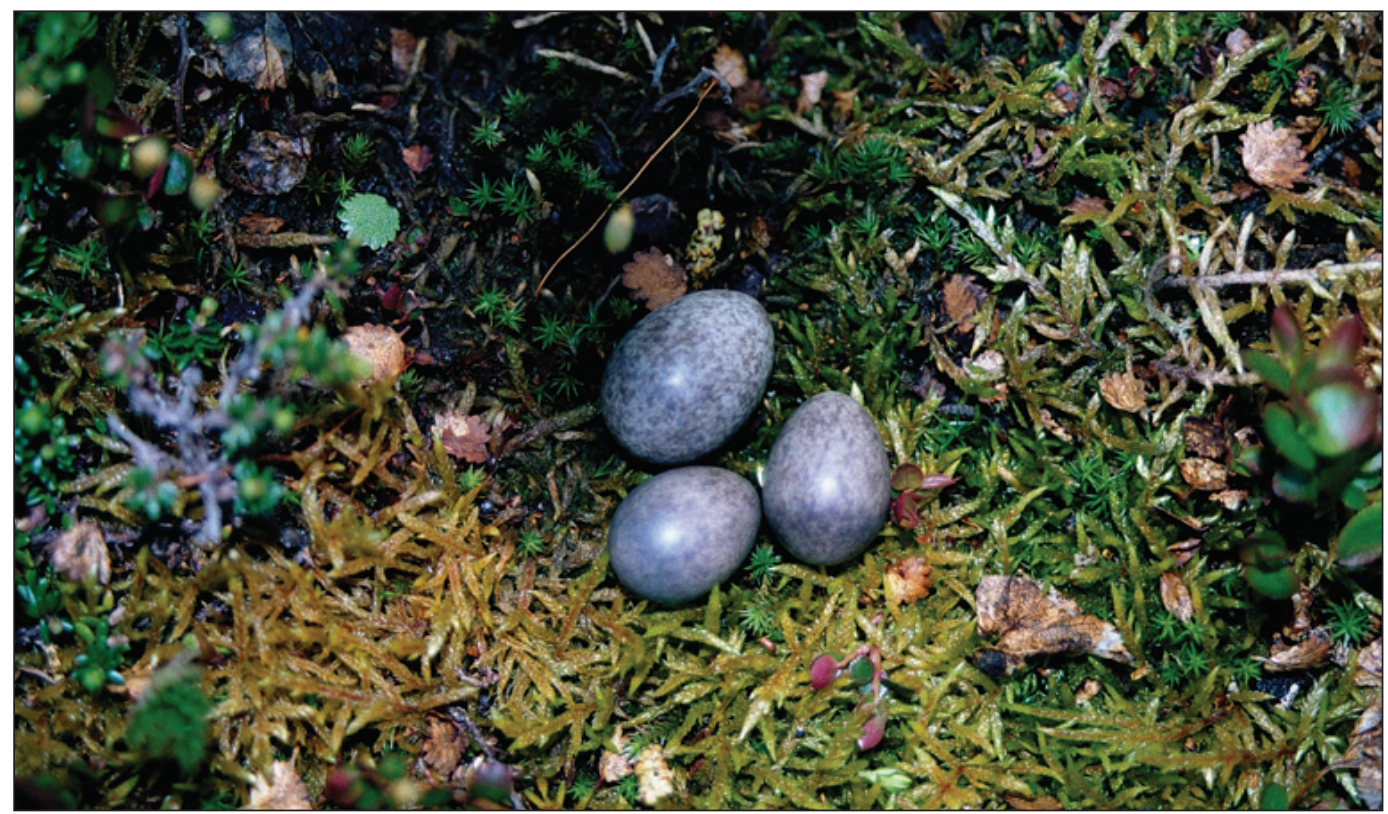

Figur 4. Egg $i$ et heipiplerkereir fra Filefjell i 2002, merket H2002gFilefjell. Eggmimikry kan bedømmes av bildet. Gjøkeggets farge preges ikke av brunlig farge slik som de fem gjøkeggene fra Øyerfjellet i 2005. Foto: Jan Berstad. 